Article

\title{
An Efficient, Eco-friendly and Sustainable One-Pot Synthesis of 3,4-Dihydropyrimidin-2(1H)-ones Directly from Alcohols Catalyzed by Heteropolyanion-Based Ionic Liquids
}

\author{
Renzhong Fu (i), Yang Yang * (D), Xudong Ma, Yu Sun, Jin Li, Hang Gao, Huaxing Hu, \\ Xiaojun Zeng and Jun Yi * \\ Jiangsu Laboratory of Advanced Functional Material, School of Chemistry and Materials Engineering, \\ Changshu Institute of Technology, Changshu 215500, China; renzhongfujs@126.com (R.F.); \\ 18852981193@163.com (X.M.); sy1885298@126.com (Y.S.); 18114760793@163.com (J.L.); \\ 18020220376@163.com (H.G.); vsm6034@163.com (H.H.); zengxiaojun@cslg.edu.cn (X.Z.) \\ * Correspondence: yangyangirisjs@126.com (Y.Y.); yijun08@mail.ustc.edu.cn (J.Y.); \\ Tel.: +86-512-5225-1842 (Y.Y. \& J.Y.)
}

Received: 22 August 2017; Accepted: 7 September 2017; Published: 11 September 2017

\begin{abstract}
Efficient, eco-friendly and sustainable access to 3,4-dihydropyrimidin-2(1H)-ones directly from alcohols under microwave and solvent-free conditions has been reported. The practical protocol involves heteropolyanion-based catalyzed oxidation of alcohols to aldehydes with $\mathrm{NaNO}_{3}$ as the oxidant followed by cyclocondensation with dicarbonyl compounds and urea or thiourea in a two-step, one-pot manner. Compatibility with different functional groups, good to excellent yields and reusable catalysts are the main highlights. The utilization of alcohols instead of aldehydes is a valid and green alternative to the classical Biginelli reaction.
\end{abstract}

Keywords: Biginelli reaction; ionic liquid; microwave; oxidative cyclocondensation; solvent-free

\section{Introduction}

One-pot, sequential multi-step reactions have become an important area of research in organic chemistry, due to the improved atom economy, multiple-bond-forming efficiency, time and energy savings and avoiding waste and pollution [1-5]. Aldehydes are widely prevalent substrates in many efficient one-pot synthesis or multicomponent reactions (MCRs) [6-8]. However, they are generally very volatile, toxic and unstable, especially due to ease of aerial oxidation. In the practical process, aldehydes must be purified carefully just before use, otherwise the impurities will affect not only the concentration of the active aldehyde, but also the proceeding of the chemical reactions. It is apparent that these disadvantages have limited the application in industry. Recently, tandem oxidation processes (TOPs) in which oxidation of alcohols combined with the subsequent elaboration of the carbonyl intermediates (aldehydes) have gained considerable attention [9-18], while only a few reports described the combining alcohol oxidation with a MCR in a one-pot process $[19,20]$. Therefore, it is expected that the use of a single vessel oxidation-MCR protocol from alcohols would widen significantly the versatility and scope of aldehyde-based MCRs.

The century-old Biginelli reaction, which involves the one-pot condensation of an aldehyde, $\beta$-ketoester and urea or thiourea gives straightforward access to functionalized 3,4-dihydropyrimidin2(1H)-ones (DHPMs) with a diverse range of biological properties [21-26], and is considered to be one of the most useful MCR [27-31]. Since the discovery of this reaction, a number of improved catalytic systems have been developed, such as Brønsted acids [32-38] or bases [39,40], metal Lewis acids [41-50], organocatalysts [51-58], and heterogeneous catalysts [59-71]. However, to the best of 
our knowledge, there have been only a few reports on the Biginelli reaction starting directly from alcohols [72-75].

With the common goal of being environmentally benign and allowing sustainable development in the chemical industry, the use of more eco-benign catalytic systems which are simple to recover helps to minimize waste production and maximize catalyst efficiency; this has been well studied in the past decades [76-78]. Among those, ionic liquids (ILs) have offered both economic and ecological benefits as ecofriendly and efficient alternatives to traditional organic solvents or catalysts $[79,80]$. In particular, a series of heteropolyanion-based ILs (HPAILs) [81-83], which were prepared by combining Keggin heteropolyanions with 'task-specific' IL cations containing special functional groups, are recently emerging as new species of hybrid materials $[84,85]$. In addition, reactions containing HPAILs are an attractive alternative for traditional acid-catalyzed [86-91] or oxidative [92-99] organic transformations because of their operational simplicity, lack of toxicity, ease of isolation and reusability. Therefore, HPAILs have proven to be a novel candidate for green and sustainable catalysts.

Recently, a large number of publications have clearly shown that the main benefit of microwave (MW) chemical processing is the significant rate enhancements, yield and selectivity improvements as well as less environmental pollution, matching with the goals of green chemistry [100-102]. Following our continued investigation into the development of useful and sustainable synthetic methodologies [103-111]—along with recent investigations involving oxidation of alcohols and the subsequent trapping of carbonyl intermediates with appropriate nucleophiles in a one-pot operation. [112] —herein, we report an efficient and environmentally benign TOPs for the Biginelli reaction, starting directly from alcohols, using HPAILs as catalysts and $\mathrm{NaNO}_{3}$ as an oxidant under MW and solvent-free conditions (Scheme 1). Compared with existing reports [72-75], short reaction times and reusable catalysts are the main highlights of this methodology.

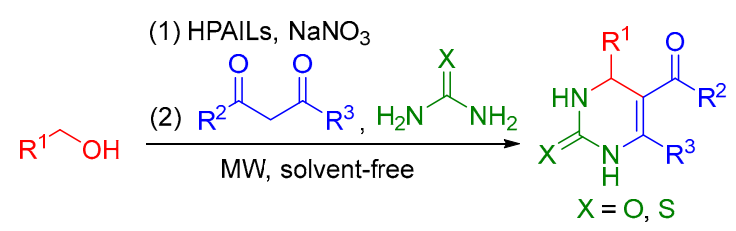

Scheme 1. Tandem oxidation process (TOP) for the Biginelli reaction starting directly from alcohols.

\section{Results and Discussion}

Based on our previous investigations into HPAILs catalyzed reactions [103-112], N-substituted imidazole, pyridine and triethylamine based HPAILs were chosen as potential catalysts for this tandem oxidative cyclocondensation (Figure 1).

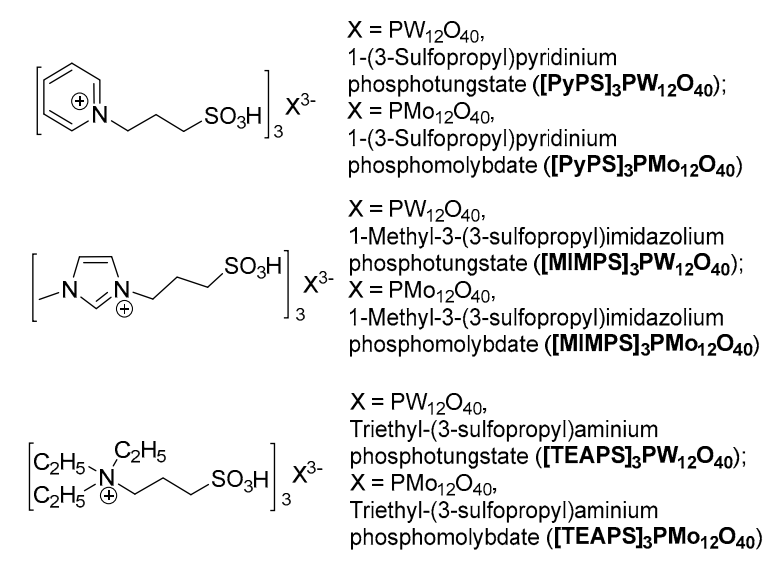

Figure 1. N-substituted imidazole, pyrdine and triethylamine based heteropolyanion-based ionic liquids (HPAILs). 
Initially, benzyl alcohol ( $3 \mathrm{mmol})$, ethylacetoacetate $(3 \mathrm{mmol})$ and urea $(4.5 \mathrm{mmol})$ were considered as standard model substrates to optimize the reaction conditions (Table 1). Firstly, we studied the tandem oxidative cyclocondensation using $\mathrm{NaNO}_{3}(3 \mathrm{mmol})$ as the oxidant in the presence of $[\mathrm{PyPS}]_{3} \mathrm{PW}_{12} \mathrm{O}_{40}(3 \mathrm{~mol} \%)$ as catalyst at $80{ }^{\circ} \mathrm{C}$ under $\mathrm{MW}$ and solvent-free conditions in a one-step one-pot procedure, disappointingly the designed product was observed in only $13 \%$ yield even after long reaction times (Table 1, entry 1). However, to our delight, the DHPM was formed in 51\% yield when ethyl acetoacetate and urea were added to the reaction mixture after the oxidation of alcohol to aldehyde was complete (Table 1, entry 2). Therefore, we aimed to accomplish the tandem oxidative cyclocondensation in a two-step one-pot manner. In order to improve the yield, some adjustments to the reaction conditions were made. It should be seen that higher temperature $\left(100{ }^{\circ} \mathrm{C}\right)$ was harmful to the oxidation of alcohol due to the partial over-oxidation (Table 1, entry 3), whereas an obvious increased yield was obtained when the cyclocondensation was performed at higher temperature $\left(100{ }^{\circ} \mathrm{C}\right.$ and $120{ }^{\circ} \mathrm{C}$ ) (Table 1, entries 4-5). In addition, more efficient results were observed by increasing the catalyst loading to $4 \mathrm{~mol} \%$ and $5 \mathrm{~mol} \%$ (Table 1, entries 6-7). Afterwards, the catalytic activities of other related catalysts prepared earlier were screened (Table 1, entries 8-12). It is expected that PyPS (1-(3-Sulfopropyl)pyridinium) species were found to be more efficient than MIMPS (1-Methyl-3-(3-sulfopropyl)imidazolium) and TEAPS (Triethyl-(3-sulfopropyl)aminium) species, while the results demonstrated that $\mathrm{PW}_{12} \mathrm{O}_{40}$ heteropolyanions were more active than $\mathrm{PMo}_{12} \mathrm{O}_{40}$ heteropolyanions. Although pure HPA (heteropolyacid) catalyst $\mathrm{H}_{3} \mathrm{PW}_{12} \mathrm{O}_{40}$ gave a moderate yield of $63 \%$, its high solubility throughout organic solvents and water made its isolation from the reaction mixture difficult (Table 1, entry 13). Finally, an optimum result was obtained when the reaction was performed using $4 \mathrm{~mol} \%$ of $[\mathrm{PyPS}]_{3} \mathrm{PW}_{12} \mathrm{O}_{40}$ at $80 / 120{ }^{\circ} \mathrm{C}$ under $\mathrm{MW}$ and solvent-free conditions affording DHPM in $92 \%$ yield (Table 1 , entry 6 ).

Table 1. Optimization of the reaction conditions for benzyl alcohol, ethylacetoacetate and urea. ${ }^{\text {a }}$

\begin{tabular}{ccccc}
\hline Entry & Catalyst $(\mathbf{m o l} \mathbf{\%})$ & $\left.\mathbf{T}^{\mathbf{1}} \mathbf{b} / \mathbf{T}^{\mathbf{2} \mathbf{c}} \mathbf{}^{\mathbf{C}} \mathbf{C}\right)$ & $\mathbf{t}^{\mathbf{1}} \mathbf{d} / \mathbf{t}^{\mathbf{2}} \mathbf{~ ( m i n )}$ & Yield $^{\mathbf{f}} \mathbf{( \% )}$ \\
\hline $1 \mathrm{~g}$ & {$[\mathrm{PyPS}]_{3} \mathrm{PW}_{12} \mathrm{O}_{40}(3)$} & 80 & 120 & 13 \\
2 & {$[\mathrm{PyPS}]_{3} \mathrm{PW}_{12} \mathrm{O}_{40}(3)$} & $80 / 80$ & $5 / 30$ & 51 \\
3 & {$[\mathrm{PyPS}]_{3} \mathrm{PW}_{12} \mathrm{O}_{40}(3)$} & $100 / 80$ & $5 / 30$ & 35 \\
4 & {$[\mathrm{PyPS}]_{3} \mathrm{PW}_{12} \mathrm{O}_{40}(3)$} & $80 / 100$ & $5 / 10$ & 78 \\
5 & {$[\mathrm{PyPS}]_{3} \mathrm{PW}_{12} \mathrm{O}_{40}(3)$} & $80 / 120$ & $5 / 5$ & 90 \\
6 & {$[\mathrm{PyPS}]_{3} \mathrm{PW}_{12} \mathrm{O}_{40}(4)$} & $80 / 120$ & $5 / 5$ & 92 \\
7 & {$[\mathrm{PyPS}]_{3} \mathrm{PW}_{12} \mathrm{O}_{40}(5)$} & $80 / 120$ & $5 / 5$ & 91 \\
8 & {$[\mathrm{PyPS}]_{3} \mathrm{PMo}_{12} \mathrm{O}_{40}(4)$} & $80 / 120$ & $5 / 5$ & 84 \\
9 & {$[\mathrm{MIMPS}]_{3} \mathrm{PW}_{12} \mathrm{O}_{40}(4)$} & $80 / 120$ & $5 / 5$ & 90 \\
10 & {$\left[\mathrm{MIMPS}{ }_{3} \mathrm{PMo}_{12} \mathrm{O}_{40}(4)\right.$} & $80 / 120$ & $5 / 5$ & 80 \\
11 & {$[\mathrm{TEAPS}]_{3} \mathrm{PW}_{12} \mathrm{O}_{40}(4)$} & $80 / 120$ & $5 / 5$ & 78 \\
12 & {$[\mathrm{TEAPS}]_{3} \mathrm{PMo}_{12} \mathrm{O}_{40}(4)$} & $80 / 120$ & $5 / 5$ & 71 \\
13 & $\mathrm{H}_{3} \mathrm{PW}_{12} \mathrm{O}_{40}(4)$ & $80 / 120$ & $5 / 5$ & 63 \\
\hline
\end{tabular}

\footnotetext{
a Reaction conditions: benzyl alcohol $(3.0 \mathrm{mmol})$, ethylacetoacetate $(3.0 \mathrm{mmol})$, urea $(4.5 \mathrm{mmol}), \mathrm{NaNO}_{3}(3 \mathrm{mmol})$ and HPAIL catalyst under microwave (MW) $(700 \mathrm{~W})$ and solvent-free condition in the two-step one-pot procedure; ${ }^{b}$ Temperatures for oxidation of alcohols; ${ }^{\mathrm{c}}$ Temperatures for cyclocondensations; ${ }^{\mathrm{d}}$ Reaction times for oxidation of alcohols; ${ }^{\mathrm{e}}$ Reaction times for cyclocondensations; ${ }^{\mathrm{f}}$ Isolated yields based on benzyl alcohol; ${ }^{\mathrm{g}}$ Reaction was conducted in the one-step one-pot procedure.
}

To explore the scope and generality of this reaction, we extended the procedure to aromatic, heterocyclic, and aliphatic alcohols. In all cases, the reaction proceeded smoothly to afford the corresponding DHPMs within short reaction times (10-18 min) in good to excellent yields (71-95\%) (Table 2). It could be noticed that a wide range of aryl alcohols bearing electron-withdrawing groups or electron-donating groups afforded good yields of DHPMs (Table 2, entries 1-7 and 11-28). Another important feature of this procedure is the compatibility with a variety of functional groups such as alkyl, alkoxyl, halide, nitro and hydroxyl under the present reaction conditions. Meanwhile, besides $\beta$-ketoesters, $\beta$-diketones (Table 2, entries 23-28) could also be employed with 
similar success to provide the corresponding products. In addition, the reactions with both urea and thiourea resulted in corresponding Biginelli adducts with good yields; nevertheless, longer reaction times were required in the cases of thiourea. It is worth mentioning that good yields were achieved (71-84\% yield) in the cases of heterocyclic and aliphatic aldehydes (Table 2, entries 8-10), which normally were less reactive or completely inert in the Biginelli reaction.

Table 2. Scope of the Biginelli reaction starting directly from alcohols. ${ }^{\text {a }}$

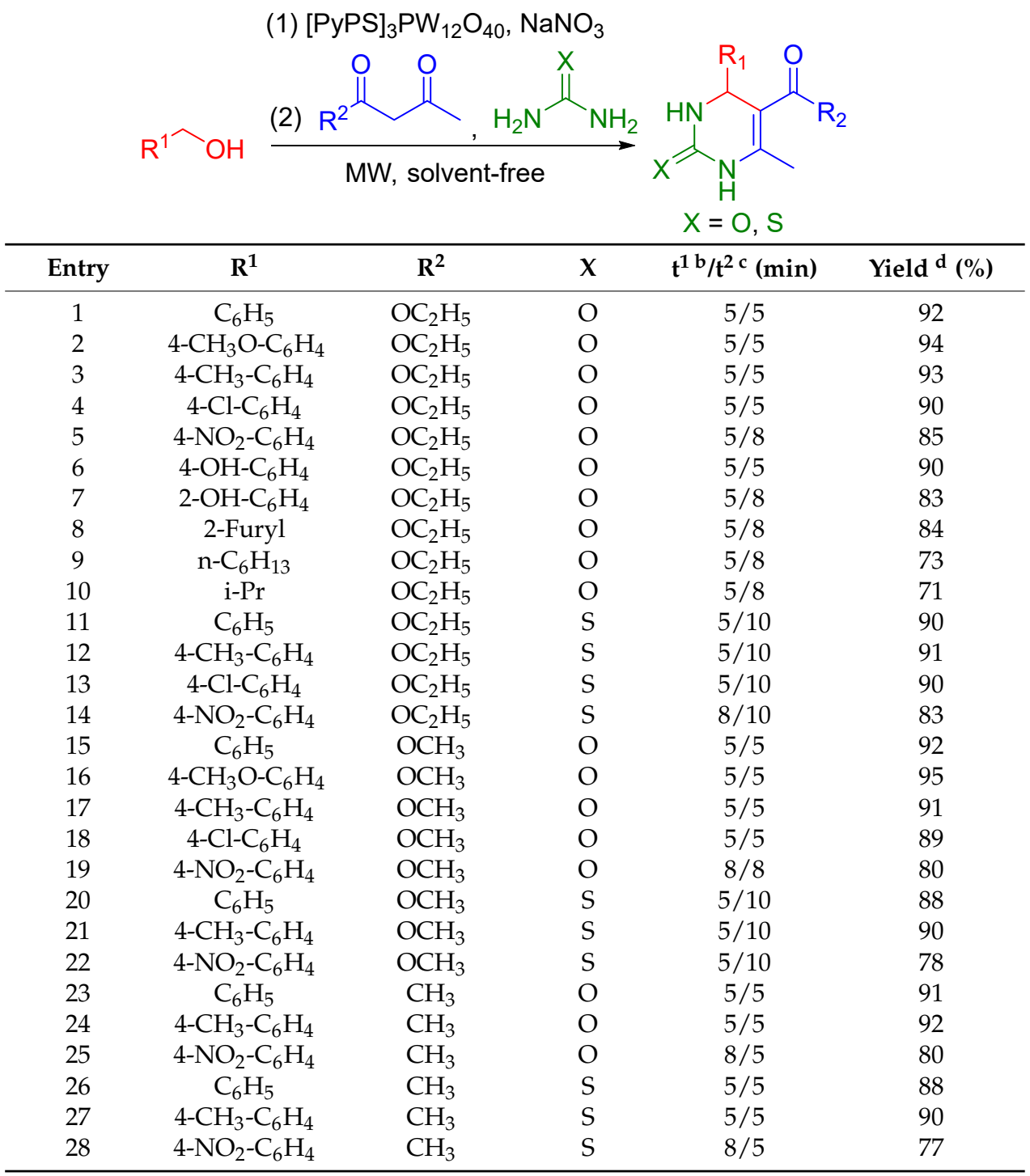

a Reaction conditions: alcohol (3.0 mmol), 1,3-dicarbonyl compound (3.0 mmol), urea or thiourea (4.5 mmol), $\mathrm{NaNO}_{3}(3 \mathrm{mmol})$ and $[\mathrm{PyPS}]_{3} \mathrm{PW}_{12} \mathrm{O}_{40}(4 \mathrm{~mol} \%)$ at $80 / 120{ }^{\circ} \mathrm{C}$ under $\mathrm{MW}(700 \mathrm{~W})$ and solvent-free condition in the two-step one-pot procedure; ${ }^{b}$ Reaction times for oxidation of alcohols; ${ }^{c}$ Reaction times for cyclocondensations; ${ }^{\mathrm{d}}$ Isolated yields based on alcohols.

In consideration of sustainable chemistry, the potential recycling of HPAILs was investigated with the reaction of benzyl alcohol, ethylacetoacetate and urea. Upon completion of the reaction in the first run, hot EtOAc was added to the reaction mixture in order to dissolve the final DHPM product. After vigorous stirring, the solid catalyst can be easily retrieved by simple filtration as well as washing with ethyl acetate and then ice water to remove traces of the previous reaction mixture and inorganic salt. After concentration of the filtrate, the almost pure product was obtained and recrystallization could be used for further purification. The recovered catalyst was used for further 
runs of the same reaction. As is evident from Figure 2, the reaction was repeated for up to five consecutive runs with a little loss of catalytic efficiency. Thus, the robustness of the catalyst and its reusability were demonstrated.

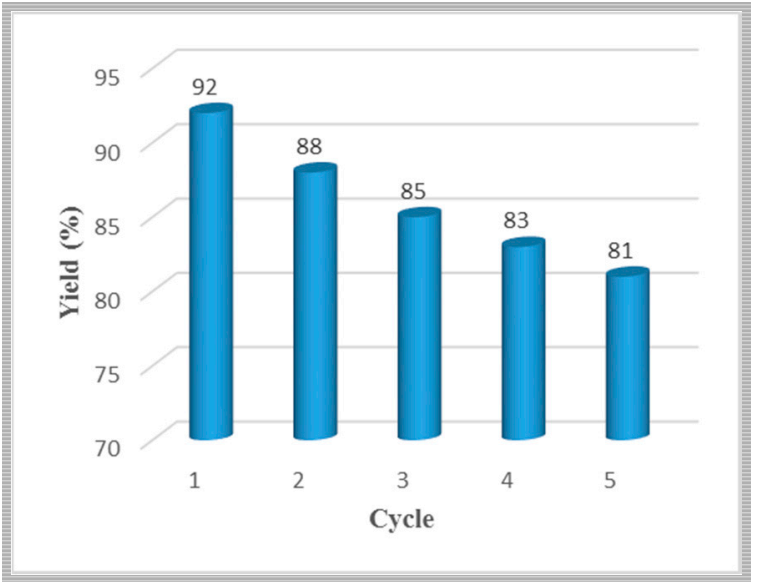

Figure 2. Reusability studies of the catalyst for the Biginelli reaction starting directly from alcohols.

Although the mechanism of Biginelli reaction has been a topic of much debate [27-31], the acidic proton and the cation of HPAIL appeared to play important roles in this tandem oxidative cyclocondensation based on the above discussions. Thus, according to the iminium route mechanism suggested by Folkers, Johnson and Kappe [113-115], a plausible mechanism for the reaction is depicted in Figure 3. Initially, the alcohol substrate was easily oxidized to aldehyde by $\mathrm{NaNO}_{3}$ with assistance of the acidic HPAIL catalyst. The catalytic cycle starts with the activation of the carbonyl of aldehyde by the coordination with an aminium cation and $\mathrm{N}-\mathrm{H}$ activation of urea by the sulfonic group in the HPAIL cation. The adsorbed aldehyde-amine species undergoes an addition of the amine to the carbonyl carbon atom to obtain the dipolar adduct. After proton-exchange, desorption and dehydration, an imine intermediate is formed with a regenerated HPAIL catalyst. Meanwhile, the HPAIL cation stabilizes the enolization of 1,3-dicarbonyl compounds to form an enolate intermediate, which undergoes the Mannich-like addition with the imine intermediate followed by intramolecular cyclocondensation. Then, the final Biginelli product is obtained, resuming the HPAIL catalyst by proton-exchange, desorption and dehydration.

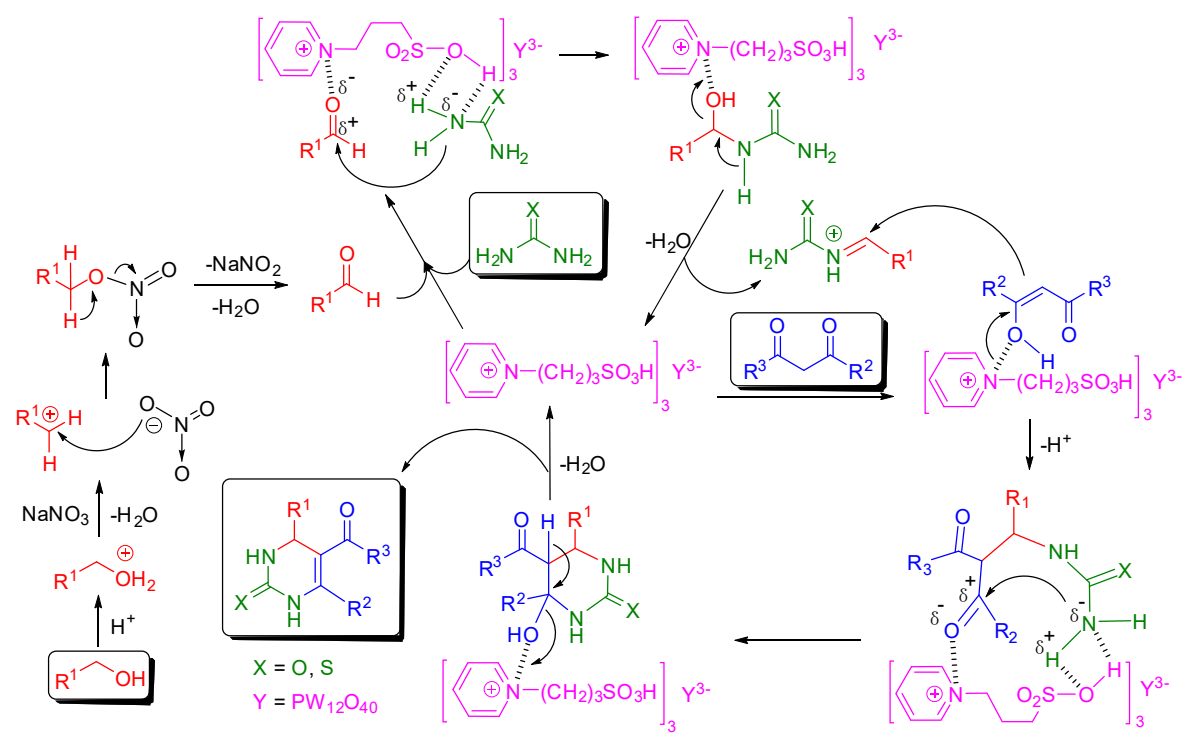

Figure 3. Plausible mechanism of HPAIL catalyzed Biginelli reaction. 


\section{Materials and Methods}

\subsection{General Methods}

Reagent grade solvents were used for extraction, recrystallization and flash chromatography. All other commercial reagents were used as received without additional purification. The progress of reactions was checked by analytical thin-layer chromatography (TLC, silica gel 60 F-254 plates) (Qingdao Haiyang Chemical Co., Ltd., Qingdao, Shandong, China). The plates were visualized first with UV illumination followed by iodine or phosphomolybdic acid hydrate. Column chromatography was performed using silica gel (200-300 mesh) (Qingdao Haiyang Chemical Co., Ltd., Qingdao, Shandong, China). NMR spectra were obtained using BRUKER AVANCE III instrument (Bruker Co., Ltd., Switzerland). ${ }^{1} \mathrm{H}-\mathrm{NMR}$ spectra were recorded at $300 \mathrm{MHz}$ or $400 \mathrm{MHz}$ and are reported in parts per million (ppm) on the $\delta$ scale relative to tetramethylsilane (TMS) as an internal standard. ${ }^{13} \mathrm{C}-\mathrm{NMR}$ spectra were recorded at $75 \mathrm{MHz}$ or $100 \mathrm{MHz}$ and are reported in parts per million (ppm) on the $\delta$ scale relative to $\mathrm{CDCl}_{3}(\delta 77.16)$ and DMSO- $d_{6}(\delta 39.52)$. Multiplicities are indicated as the following: s, singlet; d, doublet; t, triplet; q, quartet; m, multiplet; dd, doubled doublet; td, tripled doublet; br, broad. Coupling constants ( $\mathrm{v}$ values) where noted are quoted in hertz. Mass spectra were obtained using Agilent 1260-6120 (ESI) instrument (Agilent Technologies Co., Ltd., Santa Clara, CA, USA). MW-promoted heating was obtained using MAS-II instrument manufactured (Sineo Microwave Chemistry Technology Co., Ltd., Shanghai, China). The melting point was uncorrected.

\subsection{General Procedure for the Synthesis of HPAILs}

To a well-stirred mixture of $12.2 \mathrm{~g}$ 1,3-propane sulfone $(0.10 \mathrm{~mol})$ in $30 \mathrm{~mL}$ toluene was added $8.9 \mathrm{~mL}$ pyridine $(0.11 \mathrm{~mol})$. The reaction mixture was stirred for $24 \mathrm{~h}$ at $50{ }^{\circ} \mathrm{C}$ under a nitrogen atmosphere resulting in a white precipitate (PyPS). After the completion of reaction, it was cooled to room temperature. PyPS was obtained after filtration, washed with diethyl ether and dried in a vacuum. Then, $18.1 \mathrm{~g}$ PyPS $(0.09 \mathrm{~mol})$ was added to an aqueous solution of $86.4 \mathrm{~g} \mathrm{H}_{3} \mathrm{PW}_{12} \mathrm{O}_{40}$ $(0.03 \mathrm{~mol})$. After stirring at room temperature for $24 \mathrm{~h}$, the solution was removed in a vacuum to give the HPAIL product $[\mathrm{PyPS}]_{3} \mathrm{PW}_{12} \mathrm{O}_{40}$ as a solid. Thus, $[\mathrm{PyPS}]_{3} \mathrm{PMo}_{12} \mathrm{O}_{40},[\mathrm{MIMPS}]_{3} \mathrm{PW}_{12} \mathrm{O}_{40}$, [MIMPS $]_{3} \mathrm{PMo}_{12} \mathrm{O}_{40}$, [TEAPS $]_{3} \mathrm{PW}_{12} \mathrm{O}_{40}$ and [TEAPS $]_{3} \mathrm{PMo}_{12} \mathrm{O}_{40}$ were prepared using according starting materials. Characterization data and copies of NMR spectra of all products can be found in the supplementary materials.

\subsection{General Procedure for the Synthesis of 3,4-Dihydropyrimidin-2(1H)-ones}

A mixture of alcohol ( $3 \mathrm{mmol}), \mathrm{NaNO}_{3}(0.255 \mathrm{~g}, 3 \mathrm{mmol})$, and [PyPS ${ }_{3} \mathrm{PW}_{12} \mathrm{O}_{40}(0.42 \mathrm{~g}, 0.12 \mathrm{mmol})$ was added to a $30 \mathrm{~mL}$ glass pressure tube. After the pressure tube was closed, the reaction mixture was stirred at $80{ }^{\circ} \mathrm{C}$ under MW for 5-8 $\min (700 \mathrm{~W})$. After the oxidation of alcohol (monitored by TLC), 1,3-dicarbonyl compound $(3 \mathrm{mmol})$ and urea or thiourea $(4.5 \mathrm{mmol})$ were added to the reaction mixture. The mixture was heated with stirring at $120^{\circ} \mathrm{C}$ under MW for 5-10 min. On completion of the reaction (monitored by TLC), the mixture was diluted with hot ethyl acetate $(20 \mathrm{~mL})$ with stirring for $30 \mathrm{~min}$. The insoluble catalyst was recovered by filtration as well as washing with ethyl acetate and subsequent ice water to remove traces of the previous organic reaction mixture and inorganic salt. The filtrate was evaporated and the residue was obtained in near pure form. Recrystallization or column chromatography could be used for further purification. Characterization data and copies of NMR spectra of all products can be found in the supplementary materials.

\section{Conclusions}

In conclusion, all the above results demonstrate that an efficient, eco-friendly and sustainable approach for the Biginelli reaction starting directly from alcohols using $\mathrm{NaNO}_{3}$-HPAIL system was achieved. The protocol provides compatibility with various functional groups and moderate to excellent yields to afford DHPMs in a two-step one-pot process. Moreover, the HPAILs are 
recyclable and reused for more than five cycles. The present work complements the well-known Biginelli reaction. Thus, the expansion as a valid and green alternative to other aldehyde-based MCRs is currently underway.

Supplementary Materials: Supplementary materials are available online.

Acknowledgments: Financial Support from the Suzhou Science and Technology Project (Grant No. SNG201620), Changshu Science and Technology Project (Grant No. CN201714), Natural Science Foundation of Jiangsu Province (Grant No. BK20161267 and BK20160405), National Natural Science Foundation of China (Grant No. 21302013 and 21602017) and Qinglan Project of Jiangsu Province.

Author Contributions: Y.Y. and J.Y. conceived and designed the experiments; R.F., X.M., Y.S. and J.L. performed the experiments; H.G., H.H. and X.Z. checked and analyzed the data; R.F. wrote the paper; X.Z., Y.Y. and J.Y. revised the manuscript; all authors read and approved the final manuscript.

Conflicts of Interest: The authors declare no conflict of interest.

\section{References}

1. Tietze, L.F. Domino reactions in organic synthesis. Chem. Rev. 1996, 96, 115-136. [CrossRef] [PubMed]

2. Climent, M.J.; Corma, A.; Iborra, S. Heterogeneous catalysts for the one-pot synthesis of chemicals and fine chemicals. Chem. Rev. 2011, 111, 1072-1133. [CrossRef] [PubMed]

3. Pellissier, H. Stereocontrolled domino reactions. Chem. Rev. 2013, 113, 442-524. [CrossRef] [PubMed]

4. Wang, J.; Wang, X.; Xue, W.; Chen, G.; Zhang, W.; Zhu, X. Initiator and photocatalyst-free visible light induced one-pot reaction: Concurrent RAFT polymerization and CuAAC Click reaction. Macromol. Rapid Commun. 2016, 37, 799-804. [CrossRef] [PubMed]

5. Bai, S.; Jiang, L.; Zuo, J.; Hor, T.S.A. Hybrid NS ligands supported Cu(I)/(II) complexes for azide-alkyne cycloaddition reactions. Dalton Trans. 2013, 42, 11319-11326. [CrossRef] [PubMed]

6. Yan, C.G.; Wang, Q.F.; Song, X.K.; Sun, J. One-step synthesis of pyrido[1,2-a]benzimidazole derivatives by a novel multicomponent reaction of chloroacetonitrile, malononitrile, aromatic aldehyde, and pyridine. J. Org. Chem. 2009, 74, 710-718. [CrossRef] [PubMed]

7. Feng, H.; Ermolat'ev, D.S.; Song, G.; Eycken, E.V.V. Synthesis of symmetric 1,4-diamino-2-butynes via a $\mathrm{Cu}(\mathrm{I})$-catalyzed one-pot A3-coupling/decarboxylative coupling of a propiolic acid, an aldehyde, and an amine. J. Org. Chem. 2012, 77, 5149-5154. [CrossRef] [PubMed]

8. Guchhait, S.K.; Chandgude, A.L.; Priyadarshani, G. $\mathrm{CuSO}_{4}$-glucose for in situ generation of controlled $\mathrm{Cu}(\mathrm{I})-\mathrm{Cu}(\mathrm{II})$ bicatalysts: Multicomponent reaction of heterocyclic azine and aldehyde with alkyne, and cycloisomerization toward synthesis of N-fused imidazoles. J. Org. Chem. 2012, 77, 4438-4444. [CrossRef] [PubMed]

9. Reid, M.; Rowe, D.J.; Taylor, R.J.K. Two carbon homologated $\alpha, \beta$-unsaturated aldehydes from alcohols using the in situ oxidation-Wittig reaction. Chem. Commun. 2003, 2284-2285. [CrossRef]

10. Taylor, R.J.K.; Reid, M.; Foot, J.; Raw, S.A. Tandem oxidation processes using manganese dioxide: discovery, applications, and current studies. Acc. Chem. Res. 2005, 38, 851-869. [CrossRef] [PubMed]

11. Quesada, E.; Taylor, R.J.K. One-pot conversion of activated alcohols into terminal alkynes using manganese dioxide in combination with the Bestmann-Ohira reagent. Tetrahedron Lett. 2005, 46, 6473-6476. [CrossRef]

12. Phillips, D.J.; Pillinger, K.S.; Wei, L.; Taylor, A.E.; Graham, A.E. Desymmetrization of diols by a tandem oxidation/Wittig olefination reaction. Chem. Commun. 2006, 2280-2282. [CrossRef] [PubMed]

13. McAllister, G.D.; Oswald, M.F.; Paxton, R.J.; Raw, S.A.; Taylor, R.J.K. The direct preparation of functionalised cyclopropanes from allylic alcohols or $\alpha$-hydroxyketones using tandem oxidation processes. Tetrahedron 2006, 62, 6681-6694. [CrossRef]

14. Donald, J.R.; Edwards, M.G.; Taylor, R.J.K. Tandem oxime formation-Epoxide ring opening sequences for the preparation of oxazines related to the trichodermamides. Tetrahedron Lett. 2007, 48, 5201-5204. [CrossRef]

15. Bromley, W.J.; Gibson, M.; Lang, S.; Raw, S.A.; Whitwood, A.C.; Taylor, R.J.K. Tandem inverse electron demand Diels-Alder, retro-Diels-Alder and intramolecular Diels-Alder sequences: One-pot synthesis of diaza-polycycles. Tetrahedron 2007, 63, 6004-6014. [CrossRef]

16. Ekoue-Kovi, K.; Wolf, C. One-pot oxidative esterification and amidation of aldehydes. Chem. Eur. J. 2008, 14, 6302-6315. [CrossRef] [PubMed] 
17. Davi, M.; Lebel, H. Copper-Catalyzed Tandem Oxidation-Olefination Process. Org. Lett. 2009, 11, 41-44. [CrossRef] [PubMed]

18. Maki, B.E.; Scheidt, K.A. Single-flask synthesis of $N$-acylated indoles by catalytic dehydrogenative coupling with primary alcohols. Org. Lett. 2009, 11, 1651-1654. [CrossRef] [PubMed]

19. Ngouansavanh, T.; Zhu, J. Alcohols in isonitrile-based multicomponent reaction: passerini reaction of alcohols in the presence of O-iodoxybenzoic acid. Angew. Chem. Int. Ed. 2006, 45, 3495-3497. [CrossRef] [PubMed]

20. Brioche, J.; Masson, G.; Zhu, J. Passerini three-component reaction of alcohols under catalytic aerobic oxidative conditions. Org. Lett. 2010, 12, 1432-1435. [CrossRef] [PubMed]

21. Deshmukh, M.B.; Salunkhe, S.M.; Patil, D.R.; Anbhule, P.V. A novel and efficient one step synthesis of 2-amino-5-cyano-6-hydroxy-4-aryl pyrimidines and their anti-bacterial activity. Eur. J. Med. Chem. 2009, 44, 2651-2654. [CrossRef] [PubMed]

22. Singh, K.; Arora, D.; Poremsk, E.; Lowery, J.; Moreland, R.S. N1-Alkylated 3,4-dihydropyrimidine-2(1H)-ones: Convenient one-pot selective synthesis and evaluation of their calcium channel blocking activity. Eur. J. Med. Chem. 2009, 44, 1997-2001. [CrossRef] [PubMed]

23. Kumar, B.R.P.; Sankar, G.; Baig, R.B.N.; Chandrashekaran, S. Novel Biginelli dihydropyrimidines with potential anticancer activity: A parallel synthesis and CoMSIA study. Eur. J. Med. Chem. 2009, 44, 4192-4198. [CrossRef] [PubMed]

24. Da Silva, D.L.; Reis, F.S.; Muniz, D.R.; Ruiz, A.L.T.G.; de Carvalho, J.E.; Sabino, A.A.; Modolo, L.V.; de Fatima, A. Free radical scavenging and antiproliferative properties of Biginelli adducts. Bioorg. Med. Chem. 2012, 20, 2645-2650. [CrossRef] [PubMed]

25. Bagal, S.K.; Brown, A.D.; Cox, P.J.; Omoto, K.; Owen, R.M.; Pryde, D.C.; Sidders, B.; Skerratt, S.E.; Stevens, E.B.; Storer, R.I.; et al. Ion channels as therapeutic targets: A drug discovery perspective. J. Med. Chem. 2013, 56, 593-624. [CrossRef] [PubMed]

26. Kaur, R.; Chaudhary, S.; Kumar, K.; Gupta, M.K.; Rawal, R.K. Recent synthetic and medicinal perspectives of dihydropyrimidinones: A review. Eur. J. Med. Chem. 2017, 132, 108-134. [CrossRef] [PubMed]

27. Kappe, C.O. Recent advances in the Biginelli dihydropyrimidine synthesis. New tricks from an old dog. Acc. Chem. Res. 2000, 33, 879-888. [CrossRef] [PubMed]

28. Dömling, A. Recent developments in isocyanide based multicomponent reactions in applied chemistry. Chem. Rev. 2006, 106, 17-89. [CrossRef] [PubMed]

29. Dondoni, A.; Massi, A. Design and synthesis of new classes of heterocyclic c-glycoconjugates and carbon-linked sugar and heterocyclic amino acids by asymmetric multicomponent reactions (AMCRs). Acc. Chem. Res. 2006, 39, 451-463. [CrossRef] [PubMed]

30. Nagarajaiah, H.; Mukhopadhyay, A.; Moorthy, J.N. Biginelli reaction: An overview. Tetrahedron Lett. 2016, 57, 5135-5149. [CrossRef]

31. Xue, H.; Zhao, Y.; Wu, H.; Wang, Z.; Yang, B.; Wei, Y.; Wang, Z.; Tao, L. Multicomponent combinatorial polymerization via the Biginelli reaction. J. Am. Chem. Soc. 2016, 138, 8690-8693. [CrossRef] [PubMed]

32. Yu, Y.; Liu, C.; Luo, G. One-pot synthesis of 3,4-dihydropyrimidin-2(1H)-ones using chloroacetic acid as catalyst. Bioorg. Med. Chem. Lett. 2007, 17, 3508-3510. [CrossRef] [PubMed]

33. Polshettiwar, V.; Varma, R.S. Biginelli reaction in aqueous medium: A greener and sustainable approach to substituted 3,4-dihydropyrimidin-2(1H)-ones. Tetrahedron Lett. 2007, 48, 7343-7346. [CrossRef]

34. Shobha, D.; Chari, M.A.; Ahn, K.H. An efficient Biginelli one-pot synthesis of new benzoxazole-substituted dihydropyrimidinones and thiones catalysed by trifluoro acetic acid under solvent-free conditions. Chin. Chem. Lett. 2009, 20, 1059-1061. [CrossRef]

35. Wang, Y.; Yu, J.; Yang, H.; Miao, Z.; Chen, R. Solvent-free Biginelli reaction: A green method for the synthesis of 3,4-dihydropyrimidin-2-ones catalyzed by protic acids in large-scale. Lett. Org. Chem. 2011, 8, $264-267$. [CrossRef]

36. Gore, S.; Baskaran, S.; Koenig, B. Efficient synthesis of 3,4-dihydropyrimidin-2-ones in low melting tartaric acid-urea mixtures. Green Chem. 2011, 13, 1009-1013. [CrossRef]

37. Ren, Y.; Cai, C.; Yang, R. Molecular iodine-catalyzed multicomponent reactions: An efficient catalyst for organic synthesis. RSC Adv. 2013, 3, 7182-7204. [CrossRef]

38. Barbero, M.; Cadamuro, S.; Dughera, S. A Brønsted acid catalysed enantioselective Biginelli reaction. Green Chem. 2017, 19, 1529-1535. [CrossRef] 
39. Shen, Z.; Xu, X.; Ji, S. Brønsted base-catalyzed one-pot three-component Biginelli-type reaction: An efficient synthesis of 4,5,6-triaryl-3,4-dihydropyrimidin-2(1H)-one and mechanistic study. J. Org. Chem. 2010, 75, 1162-1167. [CrossRef] [PubMed]

40. Tamaddon, F.; Razmi, Z.; Jafari, A.A. Synthesis of 3,4-dihydropyrimidin-2(1H)-ones and 1,4-dihydropyridines using ammonium carbonate in water. Tetrahedron Lett. 2010, 51, 1187-1189. [CrossRef]

41. Lannou, M.; Hélion, F.; Namy, J. Applications of lanthanide trichloride hydrates, prepared from mischmetall, in the Biginelli reaction. Synlett 2008, 2008, 105-107.

42. Prodius, D.; Macaev, F.; Mereacre, V.; Shova, S.; Lutsenco, Y.; Styngach, E.; Ruiz, P.; Muraviev, D.; Lipkowski, J.; Simonov, Y.A.; et al. Synthesis and characterization of $\left\{\mathrm{Fe}_{2} \mathrm{CuO}\right\}$ clusters as precursors for nanosized catalytic system for Biginelli reaction. Inorg. Chem. Commun. 2009, 12, 642-645. [CrossRef]

43. Chitra, S.; Pandiarajan, K. Calcium fluoride: an efficient and reusable catalyst for the synthesis of 3,4-dihydropyrimidin-2(1H)-ones and their corresponding 2(1H)thione: An improved high yielding protocol for the Biginelli reaction. Tetrahedron Lett. 2009, 50, 2222-2224. [CrossRef]

44. Litvić, M.; Večenaj, I.; Ladišić, Z. M.; Lovrić, M.; Vinković, V.; Litvić, M.F. First application of hexaaquaaluminium(III) tetrafluoroborate as a mild, recyclable, non-hygroscopic acid catalyst in organic synthesis: A simple and efficient protocol for the multigram scale synthesis of 3,4-dihydropyrimidinones by Biginelli reaction. Tetrahedron 2010, 66, 3463-3471. [CrossRef]

45. Sadek, K.U.; Al-Qalaf, F.; Abdelkhalik, M.M.; Elnagdi, M.H.J. Cerium (IV) ammonium nitrate as an efficient Lewis acid for the one-pot synthesis of 3,4-dihydropyrimidin-2(1H)-ones and their corresponding 2-(1H) thiones. Heterocycl. Chem. 2010, 47, 284-286.

46. Narsaiah, A.V.; Reddy, A.R.; Yadav, J.S. Samarium triflate-catalyzed Biginelli condensation: An improved method for the synthesis of 3,4-dihydropyrimidin-2(1H)-ones. Synth. Commun. 2011, 41, 2794-2799. [CrossRef]

47. Lei, M.; Ma, L.; Hu, L. $\mathrm{Cu}\left(\mathrm{ClO}_{4}\right)_{2} \cdot 6 \mathrm{H}_{2} \mathrm{O}$ as an efficient catalyst for the synthesis of 3,4-dihydropyrimidin2(1H)-ones under solvent-free conditions. Synth. Commun. 2011, 41, 3071-3077. [CrossRef]

48. Pasunooti, K.K.; Chai, H.; Jensen, C.N.; Gorityala, B.K.; Wang, S.; Liu, X. A microwave-assisted, copper-catalyzed three-component synthesis of dihydropyrimidinones under mild conditions. Tetrahedron Lett. 2011, 52, 80-84. [CrossRef]

49. Starcevich, J.T.; Laughlin, T.J.; Mohan, R.S. Iron(III) tosylate catalyzed synthesis of 3,4-dihydropyrimidin2(1H)-ones/thiones via the Biginelli reaction. Tetrahedron Lett. 2013, 54, 983-985. [CrossRef]

50. Nguyen, N.H.T.; Nguyen, P.P.T.; Nguyen, T.T.; Tran, M.T.; Huynh, T.T.H.; Tran, P.H. Au nanorod: An efficient catalyst for one-pot synthesis of 3,4-dihydropyrimidin-2(1H)-ones via the multicomponent Biginelli reaction. Chemistryselect 2017, 2, 3932-3936. [CrossRef]

51. Mandhane, P.G.; Joshi, R.S.; Nagargoje, D.R.; Gill, C.H. An efficient synthesis of 3,4-dihydropyrimidin$2(1 H)$-ones catalyzed by thiamine hydrochloride in water under ultrasound irradiation. Tetrahedron Lett. 2010, 51, 3138-3140. [CrossRef]

52. Rao, G.B.D.; Acharya, B.N.; Verma, S.K.; Kaushik, M.P. N,N'-Dichlorobis(2,4,6-trichlorophenyl)urea (CC-2) as a new reagent for the synthesis of pyrimidone and pyrimidine derivatives via Biginelli reaction. Tetrahedron Lett. 2011, 52, 809-812. [CrossRef]

53. Silva, D.L.; Fernandes, S.A.; Sabino, A.A.; Fátima, Â. p-Sulfonic acid calixarenes as efficient and reusable organocatalysts for the synthesis of 3,4-dihydropyrimidin-2(1H)-ones/-thiones. Tetrahedron Lett. 2011, 52, 6328-6330. [CrossRef]

54. Verma, S.; Jain, S.L. Thiourea dioxide in water as a recyclable catalyst for the synthesis of structurally diverse dihydropyrido[2,3-d]pyrimidine-2,4-diones. Tetrahedron Lett. 2012, 53, 2595-2600. [CrossRef]

55. Xu, F.; Huang, D.; Lin, X.; Wang, Y. Highly enantioselective Biginelli reaction catalyzed by SPINOL-phosphoric acids. Org. Biomol. Chem. 2012, 10, 4467-4470. [CrossRef] [PubMed]

56. Nagarapu, L.; Gaikwad, H.K.; Palem, J.D.; Venkatesh, R.; Bantu, R.; Sridhar, B. Convenient approach for the one-pot, three-component synthesis of triheterocyclic $4 H$-pyrimido[2,1-b]benzothiazole derivatives using TBAHS. Synth. Commun. 2013, 43, 93-104. [CrossRef]

57. Puripat, M.; Ramozzi, R.; Hatanaka, M.; Parasuk, W.; Parasuk, V. The Biginelli reaction is a urea-catalyzed organocatalytic multicomponent reaction. J. Org. Chem. 2015, 80, 6959-6967. [CrossRef] [PubMed] 
58. Khatri, C.K.; Rekunge, D.S.; Chaturbhuj, G.U. Sulfated polyborate: A new and eco-friendly catalyst for one-pot multicomponent synthesis of 3,4-dihydropyrimidin-2(1H)-ones/thiones via Biginelli reaction. New J. Chem. 2016, 40, 10412-10417. [CrossRef]

59. Cheng, Q.; Wang, Q.; Xu, X.; Ruan, M.; Yao, H.; Yang, X. Solvent-free synthesis of monastrol derivatives catalyzed by $\mathrm{NaHSO}_{4}$. J. Heterocycl. Chem. 2010, 47, 624-628. [CrossRef]

60. Shobha, D.; Chari, M.A.; Mano, A.; Selvan, S.T.; Mukkanti, K.; Vinu, A. Synthesis of 3,4-dihydropyrimidin2-ones (DHPMs) using mesoporous aluminosilicate (AlKIT-5) catalyst with cage type pore structure. Tetrahedron 2009, 65, 10608-10611. [CrossRef]

61. Verma, S.; Jain, S.L.; Sain, B. PEG-embedded thiourea dioxide (PEG.TUD) as a novel organocatalyst for the highly efficient synthesis of 3,4-dihydropyrimidinones. Tetrahedron Lett. 2010, 51, 6897-6900. [CrossRef]

62. Murata, H.; Ishitani, H.; Iwamoto, M. Synthesis of Biginelli dihydropyrimidinone derivatives with various substituents on aluminium-planted mesoporous silica catalyst. Org. Biomol. Chem. 2010, 8, 1202-1211. [CrossRef] [PubMed]

63. Li, P.; Regati, S.; Butcher, R.J.; Arman, H.D.; Chen, Z.; Xiang, S.; Chen, B.; Zhao, C. Hydrogen-bonding 2D metal-organic solids as highly robust and efficient heterogeneous green catalysts for Biginelli reaction. Tetrahedron Lett. 2011, 52, 6220-6222. [CrossRef] [PubMed]

64. Konkala, K.; Sabbavarapu, N.M.; Katla, R.; Durga, N.Y.V.; Reddy, T.V.K.; Bethala, L.A.P.D.; Rachapudi, B.N.P. Revisit to the Biginelli reaction: a novel and recyclable bioglycerol-based sulfonic acid functionalized carbon catalyst for one-pot synthesis of substituted 3,4-dihydropyrimidin-2-(1H)-ones. Tetrahedron Lett. 2012, 53, 1968-1973. [CrossRef]

65. Narahari, S.R.; Reguri, B.R.; Gudaparthi, O.; Mukkanti, K. Synthesis of dihydropyrimidinones via Biginelli multicomponent reaction. Tetrahedron Lett. 2012, 53, 1543-1545. [CrossRef]

66. Sahu, P.K.; Sahu, P.K.; Agarwal, D.D. Efficient and facile synthesis of heterocycles and their mechanistic consideration using kaolin. RSC Adv. 2013, 3, 9854-9864. [CrossRef]

67. Shi, X.; Yang, H.; Tao, M.; Zhang, W. Sulfonic acid-functionalized polypropylene fiber: highly efficient and recyclable heterogeneous Brønsted acid catalyst. RSC Adv. 2013, 3, 3939-3945. [CrossRef]

68. Shen, P.; Xu, M.; Yin, D.; Xie, S.; Zhou, C.; Li, F. Halogenated macroporous sulfonic resins as efficient catalysts for the Biginelli reaction. Catal. Commun. 2016, 77, 18-21. [CrossRef]

69. Sheykhan, M.; Yahyazadeh, A.; Ramezani, L. A novel cooperative Lewis acid/Brønsted base catalyst $\mathrm{Fe}_{3} \mathrm{O}_{4} @ \mathrm{SiO}_{2}-\mathrm{APTMS}-\mathrm{Fe}(\mathrm{OH})_{2}$ : An efficient catalyst for the Biginelli reaction. Mol. Catal. 2017, 435, 166-173. [CrossRef]

70. Zolfagharinia, S.; Kolvari, E.; Koukabi, N. A new type of magnetically-recoverable heteropolyacid nanocatalyst supported on zirconia-encapsulated $\mathrm{Fe}_{3} \mathrm{O}_{4}$ nanoparticles as a stable and strong solid acid for multicomponent reactions. Catal. Lett. 2017, 147, 1551-1566. [CrossRef]

71. Ghosh, B. K.; Moitra, D.; Chandel, M.; Patra, M.K.; Vadera, S.R.; Ghosh, N. N. CuO nanoparticle immobilised mesoporous $\mathrm{TiO}_{2}$-cobalt ferrite nanocatalyst: A versatile, magnetically separable and reusable catalyst. Catal. Lett. 2017, 147, 1061-1076. [CrossRef]

72. Khosropour, A.R.; Khodaei, M.M.; Beygzadeh, M.; Jokar, M. A one-pot synthesis of 3,4-dihydropyrimidin2-(1H)-ones from primary alcohols promoted by $\mathrm{Bi}\left(\mathrm{NO}_{3}\right)_{3} \cdot 5 \mathrm{H}_{2} \mathrm{O}$ in two different media: organic solvent and ionic liquid. Heterocycles 2005, 65, 767-773. [CrossRef]

73. Garima; Srivastava, V.P.; Yadav, L.D.S. Biginelli reaction starting directly from alcohols. Tetrahedron Lett. 2010, 51, 6436-6438. [CrossRef]

74. Kolvari, E.; Zolfigol, M.A.; Mirzaeean, M. Aluminium nitrate nonahydrate $\left(\mathrm{Al}\left(\mathrm{NO}_{3}\right)_{3} \cdot 9 \mathrm{H}_{2} \mathrm{O}\right)$ : An efficient oxidant catalyst for the one-pot synthesis of Biginelli compounds from benzyl alcohols. Helv. Chim. Acta 2012, 95, 115-119. [CrossRef]

75. Sahoo, P.K.; Bose, A.; Mal, P. Solvent-free ball-milling Biginelli reaction by subcomponent synthesis. Eur. J. Org. Chem. 2015, 2015, 6994-6998. [CrossRef]

76. Simon, M.; Li, C. Green chemistry oriented organic synthesis in water. Chem. Soc. Rev. 2012, 41, 1415-1427. [CrossRef] [PubMed]

77. Han, X.; Poliakoff, M. Continuous reactions in supercritical carbon dioxide: Problems, solutions and possible ways forward. Chem. Soc. Rev. 2012, 41, 1428-1436. [CrossRef] [PubMed]

78. Baig, R.B.N.; Varma, R. S. Alternative energy input: Mechanochemical, microwave and ultrasound-assisted organic synthesis. Chem. Soc. Rev. 2012, 41, 1559-1584. [CrossRef] [PubMed] 
79. Xin, B.W.; Hao, J.C. Imidazolium-based ionic liquids grafted on solid surfaces. Chem. Soc. Rev. 2014, 43, 7171-7187. [CrossRef] [PubMed]

80. Wagh, K.V.; Bhanage, B.M. Synthesis of 2-phenylnaphthalenes from styrene oxides using a recyclable Brønsted acidic [HNMP] ${ }^{+} \mathrm{HSO}_{4}{ }^{-}$ionic liquid. Green Chem. 2015, 17, 4446-4451. [CrossRef]

81. Bourlinos, A.B.; Raman, K.; Herrera, R.; Zhang, Q.; Archer, L.A.; Giannelis, E.P. A liquid derivative of 12-tungstophosphoric acid with unusually high conductivity. J. Am. Chem. Soc. 2004, 126, 15358-15359. [CrossRef] [PubMed]

82. Rickert, P.G.; Antonio, M.R.; Firestone, M.A.; Kubatko, K.A.; Szreder, T.; Wishart, J.F.; Dietz, M.L. Tetraalkylphosphonium polyoxometalate ionic liquids: Novel, organic-inorganic hybrid materials. J. Phys. Chem. B 2007, 111, 4685-4692. [CrossRef] [PubMed]

83. Rickert, P.G.; Antonio, M.R.; Firestone, M.; Kubatko, A.K.A.; Szreder, T.; Wishart, J.F.; Dietz, M.L. Tetraalkylphosphonium polyoxometalates: Electroactive, "task-specific" ionic liquids. Dalton Trans. 2007, 529-531. [CrossRef] [PubMed]

84. Bai, S.; Kai, D.; Ke, K.L.; Lin, M.; Jiang, L.; Jiang, Y.; Young, D.J.; Loh, X.J.; Li, X.; Hor, T.S.A. A triazolyl-pyridine-supported CuI dimer: Tunable luminescence and fabrication of composite fibers. ChemPlusChem 2015, 80, 1235-1240. [CrossRef]

85. Teeuwen, R.L.M.; van Berkel, S.S.; van Dulmen, T.H.H.; Schoffelen, S.; Meeuwissen, S.A.; Zuilhof, H.; de Wolf, F.A.; van Hest, J.C.M. “Clickable” elastins: Elastin-like polypeptides functionalized with azide or alkyne groups. Chem. Commun. 2009, 0, 4022-4024. [CrossRef] [PubMed]

86. Leng, Y.; Wang, J.; Zhu, D.; Ren, X.; Ge, H.; Shen, L. Heteropolyanion-based ionic liquids: Reaction-induced self-separation catalysts for esterification. Angew. Chem. Int. Ed. 2009, 48, 168-171. [CrossRef] [PubMed]

87. Zhang, W.; Leng, Y.; Zhu, D.; Wu, Y.; Wang, J. Phosphotungstic acid salt of triphenyl(3-sulfopropyl)phosphonium: An efficient and reusable solid catalyst for esterification. Catal. Commun. 2009, 11, 151-154. [CrossRef]

88. Li, H.; Qiao, Y.; Hua, L.; Hou, Z.; Feng, B.; Pan, Z.; Hu, Y.; Wang, X.; Zhao, X.; Yu, Y. Imidazolium polyoxometalate: An ionic liquid catalyst for esterification and oxidative esterification. ChemCatChem 2010, 2, 1165-1170. [CrossRef]

89. Zhang, W.; Leng, Y.; Zhao, P.; Wang, J.; Zhu, D.; Huang, J. Heteropolyacid salts of N-methyl-2-pyrrolidonium as highly efficient and reusable catalysts for Prins reactions of styrenes with formalin. Green Chem. 2011, 13, 832-834. [CrossRef]

90. Fang, D.; Wang, F.; Wang, L.; Wu, Y.; Yang, J.; Qian, C. Regioselective mononitration of aromatic compounds catalyzed by heteropolyanions-based acidic ionic liquids. Curr. Catal. 2012, 1, 197-201. [CrossRef]

91. Zhang, X.; Mao, D.; Leng, Y.; Zhou, Y.; Wang, J. Heterogeneous beckmann rearrangements catalyzed by a sulfonated imidazolium salt of phosphotungstate. Catal. Lett. 2013, 143, 193-199. [CrossRef]

92. Qiao, Y.; Hou, Z.; Li, H.; Hu, Y.; Feng, B.; Wang, X.; Hua, L.; Huang, Q. Polyoxometalate-based protic alkylimidazolium salts as reaction-induced phase-separation catalysts for olefin epoxidation. Green Chem. 2009, 11, 1955-1960. [CrossRef]

93. Leng, Y.; Wang, J.; Zhu, D.; Zhang, M.; Zhao, P.; Long, Z.; Huang, J. Polyoxometalate-based amino-functionalized ionic solid catalysts lead to highly efficient heterogeneous epoxidation of alkenes with $\mathrm{H}_{2} \mathrm{O}_{2}$. Green Chem. 2011, 13, 1636-1639. [CrossRef]

94. Leng, Y.; Wang, J.; Zhu, D.; Shen, L.; Zhao, P.; Zhang, M. Heteropolyanion-based ionic hybrid solid: A green bulk-type catalyst for hydroxylation of benzene with hydrogen peroxide. Chem. Eng. J. 2011, 173, 620-626. [CrossRef]

95. Leng, Y.; Zhang, W.; Wang, J.; Jiang, P. A novel heteropolyanion-based amino-containing cross-linked ionic copolymer catalyst for epoxidation of alkenes with $\mathrm{H}_{2} \mathrm{O}_{2}$. Appl. Catal. A-Gen. 2012, 445-446, 306-311. [CrossRef]

96. Leng, Y.; Liu, J.; Zhang, C.; Jiang, P. A polyhedral oligomeric silsesquioxane (POSS)-bridged oxomolybdenum Schiff base complex with enhanced heterogeneous catalytic activity in epoxidation. Catal. Sci. Technol. 2014, 4, 997-1004. [CrossRef]

97. Long, Z. Y.; Zhou, Y.; Chen, G. J.; Ge, W.L.; Wang, J. $\mathrm{C}_{3} \mathrm{~N}_{4}-\mathrm{H}_{5} \mathrm{PMo}_{10} \mathrm{~V}_{2} \mathrm{O}_{40}$ : A dual-catalysis system for reductant-free aerobic oxidation of benzene to phenol. Sci. Rep. 2014, 4, 3651. [CrossRef] [PubMed]

98. Leng, Y.; Liu, J.; Jiang, P.; Wang, J. POSS-derived mesostructured amphiphilic polyoxometalate-based ionic hybrids as highly efficient epoxidation catalysts. ACS Sustain. Chem. Eng. 2015, 3, 170-176. [CrossRef] 
99. Leng, Y.; Zhao, J.; Jiang, P.; Wang, J. Amphiphilic porous polyhedral oligomeric silsesquioxanes (POSS) incorporated polyoxometalate-paired polymeric hybrids: Interfacial catalysts for epoxidation reactions. RSC Adv. 2015, 5, 17709-17715. [CrossRef]

100. Dallinger, D.; Kappe, C.O. Microwave-assisted synthesis in water as solvent. Chem. Rev. 2007, 107, $2563-2591$. [CrossRef] [PubMed]

101. Kappe, C.O. Microwave dielectric heating in synthetic organic chemistry. Chem. Soc. Rev. 2008, 37, 1127-1139. [CrossRef] [PubMed]

102. Polshettiwar, V.; Varma, R.S. Microwave-Assisted Organic Synthesis and Transformations using Benign Reaction Media. Acc. Chem. Res. 2008, 41, 629-639. [CrossRef] [PubMed]

103. Chen, Z.; Fu, R.; Chai, W.; Zheng, H.; Sun, L.; Lu, Q.; Yuan, R. An eco-benign and highly efficient procedure for $N$-acylation catalyzed by heteropolyanion-based ionic liquids using carboxylic acid under solvent-free conditions. Tetrahedron 2014, 70, 2237-2245. [CrossRef]

104. Fu, R.; Yang, Y.; Chen, Z.; Lai, W.; Ma, Y.; Wang, Q.; Yuan, R. Microwave-assisted heteropolyanion-based ionic liquids catalyzed transamidation of non-activated carboxamides with amines under solvent-free conditions. Tetrahedron 2014, 70, 9492-9499. [CrossRef]

105. Wang, Q.; Feng, J.; Chai, W.; Geng, H.; Xu, M.; Wang, K.; Xu, C.; Fu, R.; Yuan, R. Bu 4 NI-catalyzed construction of C-O bonds by oxidative coupling of alcohols with ethers. Tetrahedron Lett. 2014, 55, 4785-4789. [CrossRef]

106. Wang, Q.; Zheng, H.; Chai, W.; Chen, D.; Zeng, X.; Fu, R.; Yuan, R. Copper catalyzed C-O bond formation via oxidative cross-coupling reaction of aldehydes and ethers. Org. Biomol. Chem. 2014, 12, 6549-6553. [CrossRef] [PubMed]

107. Wang, Q.; Geng, H.; Chai, W.; Zeng, X.; Xu, M.; Zhu, C.; Fu, R.; Yuan, R. Copper-catalyzed formation of C-O bonds by oxidative coupling of benzylic alcohols with ethers. Eur. J. Org. Chem. 2014, 6850-6853. [CrossRef]

108. Fu, R.; Yang, Y.; Ma, Y.; Yang, F.; Li, J.; Chai, W.; Wang, Q.; Yuan, R. Microwave-promoted direct amidation of unactivated esters catalyzed by heteropolyanion-based ionic liquids under solvent-free conditions. Tetrahedron Lett. 2015, 56, 4527-4531. [CrossRef]

109. Fu, R.; Yang, Y.; Lai, W.; Ma, Y.; Chen, Z.; Zhou, J.; Chai, W.; Wang, Q.; Yuan, R. Efficient and green microwave-assisted multicomponent Biginelli reaction for the synthesis of dihydropyrimidinones catalyzed by heteropolyanion-based ionic liquids under solvent-free conditions. Synth. Commun. 2015, 45, 477-487. [CrossRef]

110. Fu, R.; Yang, Y.; Zhang, J.; Shao, J.; Xia, X.; Ma, Y.; Yuan, R. Direct oxidative amidation of aldehydes with amines catalyzed by heteropolyanion-based ionic liquids under solvent-free conditions via a dual-catalysis process. Org. Biomol. Chem. 2016, 14, 1784-1793. [CrossRef] [PubMed]

111. Fu, R.; Yang, Y.; Jin, W.; Gu, H.; Zeng, X.; Chai, W.; Ma, Y.; Wang, Q.; Yi, J.; Yuan, R. Microwave-assisted heteropolyanion-based ionic liquid promoted sustainable protocol to $N$-heteroaryl amides via $N$-directing dual catalyzed oxidative amidation of aldehydes. RSC Adv. 2016, 6, 107699-107707. [CrossRef]

112. Fu, R.; Yang, Y.; Feng, W.; Ge, Q.; Feng, Y.; Zeng, X.; Chai, W.; Yi, J.; Yuan, R. An efficient, eco-friendly and sustainable tandem oxidative amidation of alcohols with amines catalyzed by heteropolyanion-based ionic liquids via a bifunctional catalysis process. Tetrahedron 2016, 72, 8319-8326. [CrossRef]

113. Folkers, K.; Harwood, H.J.; Johnson, T.B. Researches on pyrimidines. Cxxx. Synthesis of 2-keto-1,2,3,4tetrahydropyrimidines. J. Am. Chem. Soc. 1932, 54, 3751-3758. [CrossRef]

114. Ling, R.; Yoshida, M.; Mariano, P.S. Exploratory investigations probing a preparatively versatile, pyridinium salt photoelectrocyclization-solvolytic aziridine ring opening sequence. J. Org. Chem. 1996, 61, 4439-4449. [CrossRef] [PubMed]

115. Kappe, C.O. A reexamination of the mechanism of the Biginelli dihydropyrimidine synthesis. Support for an $\mathrm{N}$-acyliminium ion intermediate. J. Org. Chem. 1997, 62, 7201-7204. [CrossRef] [PubMed]

Sample Availability: All samples are available from the authors. 